\title{
Tailored Silica Nanoparticles Surface to Increase Drug Load and Enhance Bactericidal Response
}

\author{
Luciane F. de Oliveira, ${ }^{a}$ Karim Bouchmella,${ }^{a, b}$ Agustin S. Picco, ${ }^{a, b}$ Larissa B. Capeletti, ${ }^{a, c}$ \\ Kaliandra A. Gonçalves, ${ }^{d}$ João Henrique Z. dos Santos, ${ }^{c}$ Jörg Kobarg ${ }^{e}$ and Mateus B. Cardoso ${ }^{*, a, b}$ \\ ${ }^{a}$ Laboratório Nacional de Luz Síncrotron, LNLS and ${ }^{b}$ Laboratório Nacional de Nanotecnologia, \\ LNNano, CNPEM, CP 6192, 13083-970 Campinas-SP, Brazil \\ ${ }^{c}$ Universidade Federal do Rio Grande do Sul, 91501-970 Porto Alegre-RS, Brazil \\ ${ }^{d}$ Laboratório Nacional de Biociências, LNBio, CP 6192, 13083-970 Campinas-SP, Brazil \\ ${ }^{e}$ Faculdade de Ciências Farmacêuticas e Departamento de Bioquímica e Biologia Tecidual, \\ Instituto de Biologia, Universidade Estadual de Campinas, UNICAMP, \\ CP 6154, 13083-970 Campinas-SP, Brazil
}

\begin{abstract}
Nanoparticles' surface properties can be used as triggers to regulate or even enhance biological response and generate tailored structures to substitute conventional antibiotics. Here, silica nanoparticles surface was duly tuned in order to increase the water-insoluble drug load (curcumin) and improve the antibacterial activity. Our main motivation was based on the electrostatic attraction between the positively charged amino groups and the negatively charged curcumin and/or bacteria membrane. In addition, the variation of amino grafting amount on silica nanoparticles indicated that the grafting increase was directly related to the extent of drug entrapped into the nanoparticles as well as to the bactericidal activity. The combination of amino-functionalized silica nanoparticles associated with the presence of curcumin allowed to produce a dual bactericidal system that shows promising perspective for its use in biomedical applications.
\end{abstract}

Keywords: amino-functionalized silica nanoparticles, curcumin, bactericidal activity, Escherichia coli

\section{Introduction}

Pathogenic microorganisms have proved to develop resistance to currently available antibiotics becoming a worldwide concern. ${ }^{1-5}$ Thus, it is necessary to find new systems or drugs presenting alternative mechanisms of action to substitute the existing commercial antibiotics.

Nanoparticles are promising materials for therapeutic applications since they possess unique physical and chemical properties. ${ }^{6-9}$ Thus, silica-based nanoparticles have been widely investigated and used in different fields, including materials science and biomedicine, due to their stability, high hydrophilic surface, biocompatibility and easy surface functionalization. ${ }^{10-13}$ In particular, mesoporous silica nanoparticles are potential candidates as drug carriers since they provide the possibility of encapsulating and delivering large quantities of drugs due to large surface areas and pore volumes. ${ }^{14-20}$ Using the

*e-mail: cardosomb@1nls.br, cardosomb@lnnano.cnpem.br well-known silane chemistry, silica nanoparticles have been functionalized with a variety of different functional groups such as carboxyl, ${ }^{21}$ vinyl,,${ }^{22}$ amino, ${ }^{23}$ mercapto ${ }^{24}$ and epoxy. ${ }^{25}$ The surface functionalization with organic functional groups allows increasing the storage capacity of drugs or biomolecules within the silica pores. ${ }^{21,25-28}$ Moreover, the chemical surface modification of the nanoparticles is an important tool to control the interaction of nanoparticles with biological systems while reducing toxicity and increasing the therapeutic effects..$^{29-32}$ Typical surface modification methods via covalent bonds are (i) the co-condensation (one-pot synthesis method); (ii) the postsynthetic grafting (PSG) and (iii) the use of bissilylated organic precursors that generate periodic mesoporous organosilicas (PMOs). ${ }^{33-35}$ The PSG involves modification of silica after the synthesis. In this method, it is possible to restrict the functionalization of surface-accessible silanol groups both within the mesopore network and on the exterior surfaces. Moreover, PSG has some advantages that are: the mesostructure of the starting silica phase is 
kept, the materials can be selectively functionalized with a wide variety of functional groups and the resulting structure exhibits high hydrothermal stability.

Nanostructured silica and curcumin (CCM) complexes were first reported in 2011 by Jin et al..$^{36}$ They have shown the selective immobilization of CCM onto the internal cavity of mesoporous hollow silica particles as well as their drug release properties. Later, few works ${ }^{37,38}$ have demonstrated that bare silica porous systems are able to entrap CCM and are effective against tumor cells. More recently, a plethora of works ${ }^{39-45}$ demonstrating that surface-modified curcumin-loaded silica nanoparticles can be successfully and selectively used against different types of cancer cells were reported. However, to the best of our knowledge, nothing has been done in order to use nanostructured silica and curcumin (CCM) complexes as bactericidal agents.

In our previous works, ${ }^{46-54}$ we investigated the correlation between the nanoparticles physical properties and their behavior in biological systems. These properties, that include size, surface charge and hydrophobicity, play an important role for the interaction between nanomaterials and biological systems. In the present study, we go further and show for the first time the bactericidal properties of amino-functionalized curcumin-loaded silica nanoparticles obtained from PSG method. In addition, we studied the influence on the amount of amino groups in the extent of encapsulation of curcumin and the resulting silica nanoparticles bactericidal activity. The bactericidal properties of these materials were tested against Escherichia coli (E. coli) to evaluate the aminofunctionalized silica as a platform for water-insoluble drug carrier.

\section{Experimental}

\section{Chemicals}

Tetraethoxysilane (TEOS), (3-aminopropyl) triethoxysilane (APTES), curcumin and ammonium hydroxide (26 wt.\% $\mathrm{NH}_{3}$ in water) were obtained from Sigma-Aldrich. Ethanol was obtained from J. T. Baker. Peptone, sodium chloride $(\mathrm{NaCl})$, yeast extract and bacteriological agar were purchased from Bio Rad. All chemicals and reagents were used as received without further purification. Water used in all procedures was obtained from a water purification system (Purelab from ELGA) and had a measured resistivity of $18.2 \mathrm{M} \Omega \mathrm{cm}$.

\section{Preparation of bare silica nanoparticles $\left(\mathrm{SiO}_{2}\right)$}

The bare mesoporous silica nanoparticles were prepared using the modified Stöber method. $\mathrm{SiO}_{2}$ nanoparticles were prepared by mixing $380 \mu \mathrm{L}$ of TEOS and $12 \mathrm{~mL}$ of ethanol under continuous stirring for $30 \mathrm{~min}$. Then, $570 \mu \mathrm{L}$ of $\mathrm{NH}_{4} \mathrm{OH}$ were added to the mixture and stirred for 24 hours at room temperature. The particles were separated by centrifugation (10000 rpm, 20 minutes, Eppendorf Centrifuge Model 5804), washed with ethanol and dried in air at room temperature for one day.

Amino-functionalized silica nanoparticles $\left(\mathrm{SiO}_{2}-\mathrm{NH}_{2}\right)$ synthesis

$\mathrm{SiO}_{2}-\mathrm{NH}_{2}$ nanoparticles were prepared by mixing $380 \mu \mathrm{L}$ of TEOS and $12 \mathrm{~mL}$ of ethanol under continuous stirring for $30 \mathrm{~min}$. Then, $570 \mu \mathrm{L}$ of $\mathrm{NH}_{4} \mathrm{OH}$ were added to the mixture and stirred for 24 hours at room temperature. After this time, 200 or $400 \mu \mathrm{L}$ of APTES were added to the mixture and kept under stirring for 24 hours. The particles were separated by centrifugation (10000 rpm, 20 minutes, Eppendorf Centrifuge Model 5804), washed with ethanol and dried in air at room temperature for one day.

Synthesis of amino-functionalized curcumin-loaded silica nanoparticles $\left(\mathrm{CCM} / \mathrm{SiO}_{2}-\mathrm{NH}_{2}\right)$

Amino-functionalized curcumin-loaded silica $\left(\mathrm{CCM} / \mathrm{SiO}_{2}-\mathrm{NH}_{2}\right)$ nanoparticles were prepared by mixing $380 \mu \mathrm{L}$ of TEOS, $12 \mathrm{~mL}$ of ethanol and $60 \mu \mathrm{L}$ of curcumin solution $(5 \% \mathrm{~m} / \mathrm{v})$ under continuous stirring for $30 \mathrm{~min}$. Then, $570 \mu \mathrm{L}$ of $\mathrm{NH}_{4} \mathrm{OH}$ were added to the mixture and stirred for 24 hours at room temperature. After this time, 200 or $400 \mu \mathrm{L}$ of APTES were added to the mixture and kept under stirring for 24 hours. The particles were separated by centrifugation (10000 rpm, 20 minutes, Eppendorf Centrifuge Model 5804), washed with ethanol and dried in air at room temperature for one day. Supernatant was used to determine the encapsulation yield.

\section{Ninhydrin assay}

The amino groups on the modified $\mathrm{SiO}_{2}-\mathrm{NH}_{2}$ surface were quantified with the ninhydrin assay and glycine was used as a calibrant. When ninhydrin reagent reacts with amino group produce a purple color characteristic of the ninhydrin-amino complex. The optical density is proportional to the amount of amino group. The aminofunctionalized silica nanoparticles were dispersed in a $4 \mathrm{~mL}$ of a solution containing $1 \mathrm{~mL}$ of ninhydrin solution, $2 \mathrm{~mL}$ of buffer solution, and water in 1:2:1 in volume, and then heated at $80{ }^{\circ} \mathrm{C}$ for $20 \mathrm{~min}$. Subsequently, the suspension was centrifuged at $5000 \mathrm{rpm}$ for $5 \mathrm{~min}$, the supernatant was diluted with water and its absorbance measured at 
$570 \mathrm{~nm}$ with an ultraviolet-visible spectrometer (Agilent 8453 equipment).

\section{Characterization of silica nanoparticles}

Size and morphology of the nanoparticles were investigated by transmission electron microscopy (TEM). TEM images were taken using JEOL JEM-2010 instrument at the Brazilian Laboratory of Nanosciences (LNNano) operating at an acceleration voltage of $200 \mathrm{kV}$.

The structural organization of nanoparticles was investigated through the small-angle X-ray scattering (SAXS) technique. The SAXS experiments were carried out on the D1B beamline at the LNLS using a wavelength $\lambda=1.488 \mathrm{~nm}$ and the Pilatus $300 \mathrm{k}$ detector placed $1549.8 \mathrm{~mm}$ away from the sample. The X-ray beam was monochromatized with a multilayer monochromator and collimated by a set of slits defining a pin-hole geometry. All measurements were performed at room temperature. Silver behenate powder was used as a standard to calibrate the sample-to-detector distance, the detector tilt and the direct beam position. The isotropic scattering patterns were radially averaged. Fitting procedures were carried out using the SASfit software.

The amount of entrapped curcumin was determined by the UV-Vis adsorption (measured at $520 \mathrm{~nm}$ ) taking into account the remaining curcumin in the supernatant after the reaction has been completed. The UV-Vis absorption spectra were obtained using an Agilent 8453 UV-Vis spectrophotometer (Agilent Technologies).

The nitrogen adsorption-desorption isotherms were obtained at $77 \mathrm{~K}$ using a Tristar II 3020 (Micromeretics) instrument. The specific surface area is assessed according to the standard BET (Brunauer-Emmett-Teller) method in the $0.05-0.30 \mathrm{P} / \mathrm{P}_{0}$ range. The total micropore volume of the sample was estimated using $t$-Plot analysis. The samples were degassed at $80{ }^{\circ} \mathrm{C}$ for $2 \mathrm{~h}$ under vacuum before the measurements.

The determination of surface charge of the nanoparticles was performed on a dispersion $\left(40 \mu \mathrm{g} \mathrm{mL}^{-1}\right)$ of nanoparticles in a $40 \mathrm{mmol} \mathrm{L}^{-1} \mathrm{KCl}$ solution. Complementary dynamic light scattering (DLS) experiments in biological media were performed to verify the colloidal stability of the synthesized nanoparticles. Both experiments mentioned above were performed in a Zetasizer Nano-ZS ZEN3600 instrument (Malvern Instruments Ltd., UK) operating with a He-Ne $(633 \mathrm{~nm})$ laser.

Fourier transform infrared (FTIR) spectra were recorded in a transmission mode on a PerkinElmer FT-IR spectrophotometer (model Spectrum Two) using $\mathrm{KBr}$ pellets under ambient conditions. The pellets were subjected to 32 scans at a resolution of $4 \mathrm{~cm}^{-1}$.

\section{Bactericidal susceptibility tests}

E. coli was grown in Agar plates for $16-20$ hours at $37^{\circ} \mathrm{C}$. A single colony was taken and transferred into $200 \mathrm{~mL}$ of PSI medium composed by 3.2, 2, 1, 0.08 and $0.1 \mathrm{~g}$ of peptone, yeast extract, sodium chloride, potassium dihydrogen phosphate and disodium hydrogen phosphate, respectively. The mixture was incubated for ca. 3 hours at $37{ }^{\circ} \mathrm{C}$ under vigorous shaking. The bacteria were aseptically transferred to a sterile ice-cold polypropylene tube, stored on ice for 10 minutes and centrifuged at $4000 \mathrm{rpm}$ (Thermo ScientificSorvall $\mathrm{RC}+$ ) for 15 minutes at $4{ }^{\circ} \mathrm{C}$. The pellet was resuspended in $25 \mathrm{~mL}$ of buffer $\mathrm{I}(6 \mathrm{~mL}$ solution of potassium hydroxide $1 \mathrm{~mol} \mathrm{~L}^{-1}, 6 \mathrm{~mL}$ solution of acetic acid $1 \mathrm{~mol} \mathrm{~L}^{-1}$, $10 \mathrm{~mL}$ solution of magnesium chloride $1 \mathrm{~mol} \mathrm{~L}^{-1}, 2.41 \mathrm{~g}$ of rubidium chloride, $0.294 \mathrm{~g}$ of calcium chloride and $30 \mathrm{~mL}$ glycerol $90 \%, \mathrm{pH}$ was adjusted to 5.8 in final volume of $200 \mathrm{~mL}$ ) which was stored on ice for 15 minutes followed by centrifugation at $4000 \mathrm{rpm}$ (Thermo Scientific-Sorvall RC+) for 10 minutes at $4{ }^{\circ} \mathrm{C}$. The pellet was resuspended in $8 \mathrm{~mL}$ of buffer II ( $0.42 \mathrm{~g}$ MoPs, 3-( $\mathrm{N}$-morpholino)propanesulfonic acid, $2.2 \mathrm{~g}$ of calcium chloride, $0.24 \mathrm{~g}$ of rubidium chloride, $30 \mathrm{~mL}$ glycerol $90 \%$, pH was adjusted to $7.0 \mathrm{in}$ a final volume of $200 \mathrm{~mL}$ ). $20 \mu \mathrm{L}$ of a suspension containing $E$. coli were added to a flask containing $5 \mathrm{~mL}$ of Luria Bertani (LB) broth (containing $10 \mathrm{~g} \mathrm{~L}^{-1}$ of peptone and $\mathrm{NaCl}$ and $5 \mathrm{~g} \mathrm{~L}^{-1}$ of yeast extract). The flask was stirred for 5 hours with an orbital shaker and then $1 \mu \mathrm{L}$ of this solution was diluted with $50 \mathrm{~mL}$ of LB broth. At this point, bacteria diluted suspension $(50 \mu \mathrm{L}), 1 \mathrm{~mL}$ of $\mathrm{LB}$ broth and $700 \mu \mathrm{L}$ of aqueous suspension of silica nanoparticles were mixed in the test tubes and incubated at $37^{\circ} \mathrm{C}$ under vigorous shaking (200 rpm). After $5 \mathrm{~h}$ of incubation, the bacteria growth was determined by measuring the optical density (OD) and successive dilutions were realized to reach a bacteria concentration in the range of 2000-4000 CFU mL-1. For the bactericidal susceptibility tests, $100 \mu \mathrm{L}$ of the ultimate diluted bacteria-silica solution were dispersed on a standard sized Agar plate to obtain an $E$. coli plate count in the range of 200-400 CFU. The Agar plates were incubated at $37{ }^{\circ} \mathrm{C}$ overnight. For each material, the experiments were conducted in triplicate. The same procedure described above was also performed using autoclaved water for all controls. The bactericidal activity of the materials was evaluated by counting the number of colonies formed on E. coli Agar plates.

\section{Results and Discussion}

A schematic representation for the formation and encapsulation of curcumin (CCM) into silica nanoparticles $\left(\mathrm{SiO}_{2}\right)$ is shown in Scheme 1. 

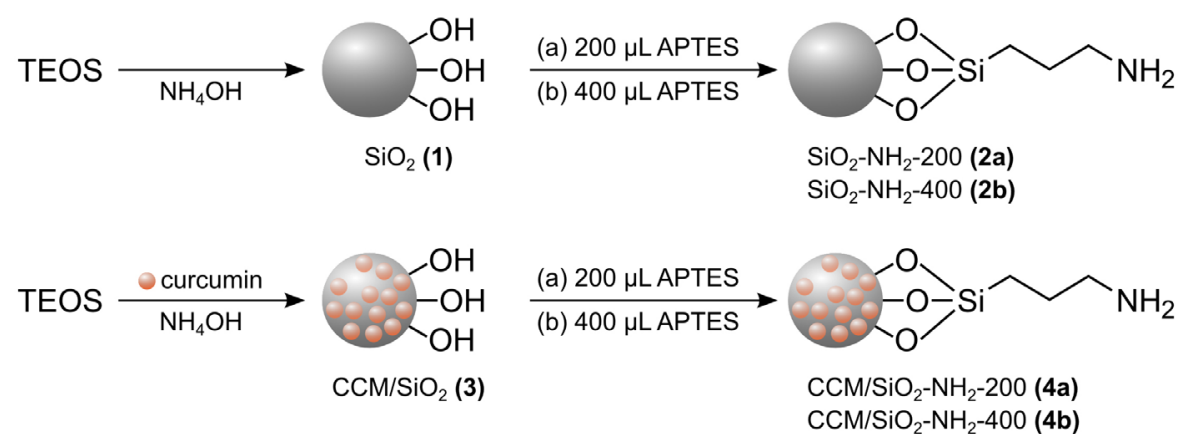

Scheme 1. Schematic representation of the synthesis of amino-functionalized silica nanoparticles with and without curcumin. A curcumin fraction is also located on the surface of the nanoparticles (3), (4a) and (4b).

Bare silica nanoparticles, $\mathrm{SiO}_{2}(\mathbf{1})$, were generated through a slightly modified Stöber method ${ }^{55}$ with tetraethyl orthosilicate (TEOS) and ammonia used as the silica precursor and catalyst, respectively. The $\mathrm{SiO}_{2}$ surface was then amino-functionalized by reacting (1) with (3-aminopropyl)-triethoxysilane (APTES) as previously described in the literature. ${ }^{56}$ Different amounts of aminopropyl groups were grafted on the $\mathrm{SiO}_{2}$ surface by changing APTES concentration used during reaction procedures (200 or $400 \mu \mathrm{L}$ resulting $\mathrm{SiO}_{2}-\mathrm{NH}_{2}-200$ (2a) or $\mathrm{SiO}_{2}-\mathrm{NH}_{2}-400$ (2b), respectively). Amino quantification on $\mathrm{SiO}_{2}-\mathrm{NH}_{2}$ surface was determined by using ninhydrin assay ${ }^{57}$ Ninhydrin reacts with amino groups to produce a characteristic purple color of the ninhydrin-amino complex. Then, the obtained optical density is proportional to the amount of amino group on the silica surface. The total amount of amino groups per gram of silica was 1.26 and $2.01 \mu \mathrm{mol}$ for $\mathrm{SiO}_{2}-\mathrm{NH}_{2}-200$ (2a) or $\mathrm{SiO}_{2}-\mathrm{NH}_{2}-400$ (2b), respectively.

The curcumin encapsulation inside silica nanoparticles was also carried out through one-pot synthesis method. First, curcumin-loaded silica nanoparticles, $\mathrm{CCM} / \mathrm{SiO}_{2}(\mathbf{3})$, were obtained by hydrolysis and condensation of TEOS in the presence of alcoholic curcumin solution. Then, $\mathrm{CCM} / \mathrm{SiO}_{2}$ (3) was amino functionalized using different amounts of APTES as the silylation agent resulting in $\mathrm{CCM} / \mathrm{SiO}_{2}-\mathrm{NH}_{2}-200$ (4a) and $\mathrm{CCM} / \mathrm{SiO}_{2}-\mathrm{NH}_{2}-400$ (4b) (200 and $400 \mu \mathrm{L}$ of APTES, respectively). The amount of curcumin encapsulated by the nanoparticles was determined by UV-Vis, subtracting the remaining amount of curcumin found in the supernatant from the total of curcumin used along the reaction procedure. We found that the curcumin entrapment yield was 15,32 and $75 \%$ for $\mathrm{CCM} / \mathrm{SiO}_{2}(3)$, $\mathrm{CCM} / \mathrm{SiO}_{2}-\mathrm{NH}_{2}-200(\mathbf{4 a})$ and $\mathrm{CCM} / \mathrm{SiO}_{2}-\mathrm{NH}_{2}-400$ (4b), respectively. Thus, amino surface functionalization plays an important role in the curcumin encapsulation yield. We attribute this encapsulation enhancement to the electrostatic attraction/repulsion forces between the main reactants of the system since curcumin and silica present negative charges while amino groups are considerably positive structures. Due to opposite charges, there will be strong affinity between amino groups and curcumin and the encapsulation will be enhanced. On the other hand, both silica and curcumin have negative charges resulting in low affinity. Thus, the low entrapment yield for $\mathrm{CCM} / \mathrm{SiO}_{2}(3)$ can be attributed to the repulsive forces between silica and curcumin.

The morphology and size distribution of the synthesized nanoparticles were primarily obtained by transmission electron microscopy (TEM). The bare silica nanoparticles (1) have a spherical structure with narrow particle size distribution of $52 \pm 13 \mathrm{~nm}$. TEM images (Figure S1, Supplementary Information section) of aminofunctionalized silica nanoparticles obtained from different amounts of aminopropyl groups show a slightly difference in size if compared to bare silica. The $\mathrm{SiO}_{2}-\mathrm{NH}_{2}-200$ (2a) nanoparticle presented a bimodal distribution with average sizes of $56 \pm 18$ and $73 \pm 7 \mathrm{~nm}$. Taking into account the area of each population, the one centered at $73 \mathrm{~nm}$ corresponds to about $30 \%$ of the total sample population. The average diameter determined through the size distribution for $\mathrm{SiO}_{2}-\mathrm{NH}_{2}-400(\mathbf{2 b})$ is $62 \pm 22 \mathrm{~nm}$. Figures $1 \mathrm{~A}$ and $1 \mathrm{C}$ present TEM images for $\mathrm{CCM} / \mathrm{SiO}_{2}-\mathrm{NH}_{2}-200$ (4a) and $\mathrm{CCM} / \mathrm{SiO}_{2}-\mathrm{NH}_{2}-400$ (4b), respectively. As expected, there was a subtle increase in particle size due to the presence of curcumin. The particle morphology was maintained and (4a) presented a bimodal distribution with average sizes of $76.4 \pm 17$ and $107.7 \pm 8 \mathrm{~nm}$ while $66 \pm 13 \mathrm{~nm}$ was observed for (4b) (Figures 1B and 1D). Taking into account the area of each population in Figure 1B, the one centered at $107.7 \mathrm{~nm}$ corresponds to about $10 \%$ of the total sample population. The nature of this bimodal distribution when we have used $200 \mu \mathrm{L}$ of APTES (samples 2a and 4a) is out of the scope of this work and has no influence on the biological results.

Complementary, we have also employed SAXS technique to determine and confirm the size and polydispersity of the synthesized nanoparticles. Figure 2 shows the experimental 

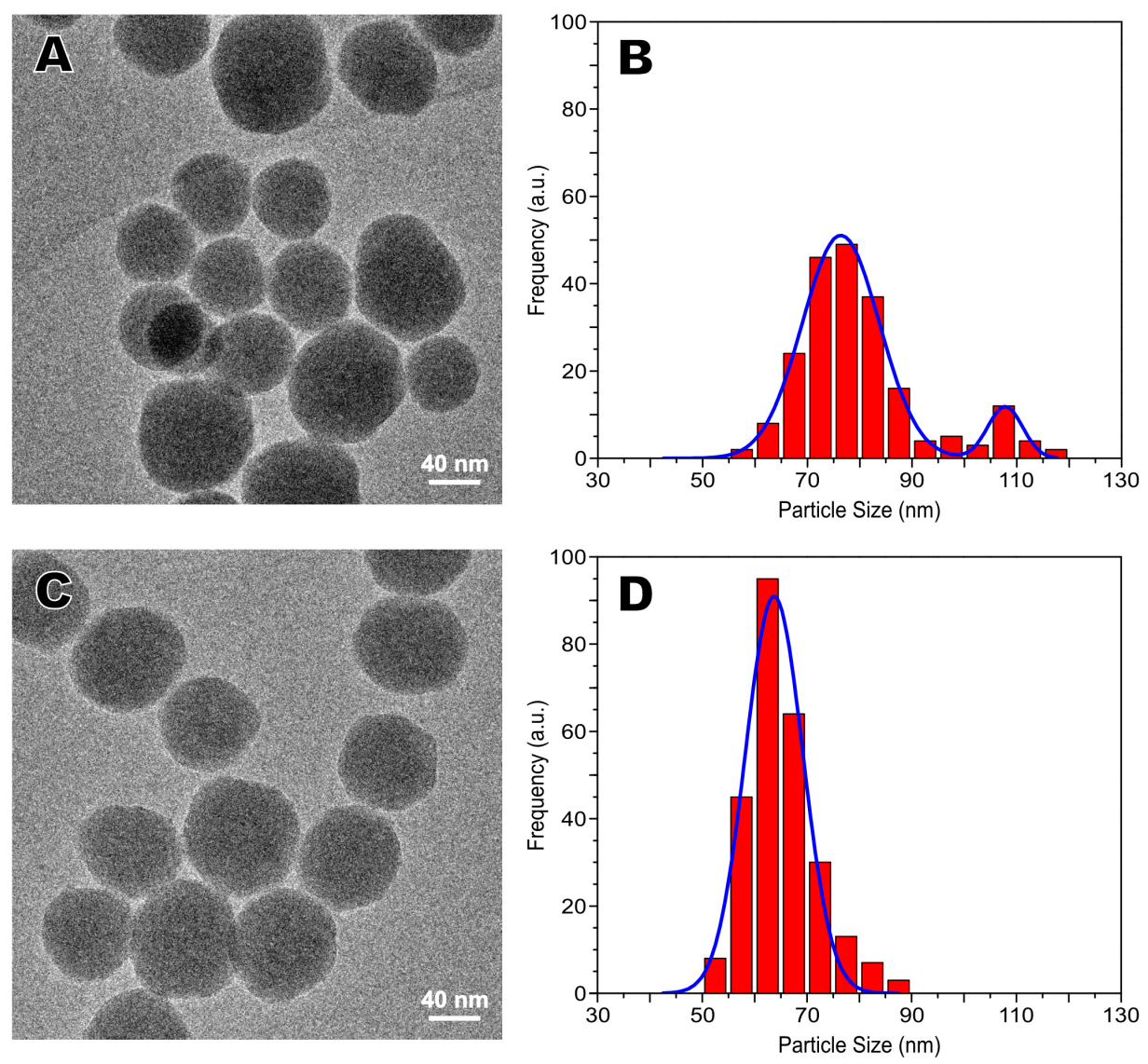

Figure 1. TEM images of (A) $\mathrm{CCM} / \mathrm{SiO}_{2}-\mathrm{NH}_{2}-200$ and (C) $\mathrm{CCM} / \mathrm{SiO}_{2}-\mathrm{NH}_{2}-400$ nanoparticles. Size distribution histograms of (B) $\mathrm{CCM} / \mathrm{SiO} \mathrm{O}_{2}-\mathrm{NH} \mathrm{H}_{2}-200$ and (D) $\mathrm{CCM} / \mathrm{SiO}_{2}-\mathrm{NH}_{2}-400$.

SAXS curve for $\mathrm{CCM} / \mathrm{SiO}_{2}-\mathrm{NH}_{2}-400(\mathbf{4 b})$ and its best corresponding fit.

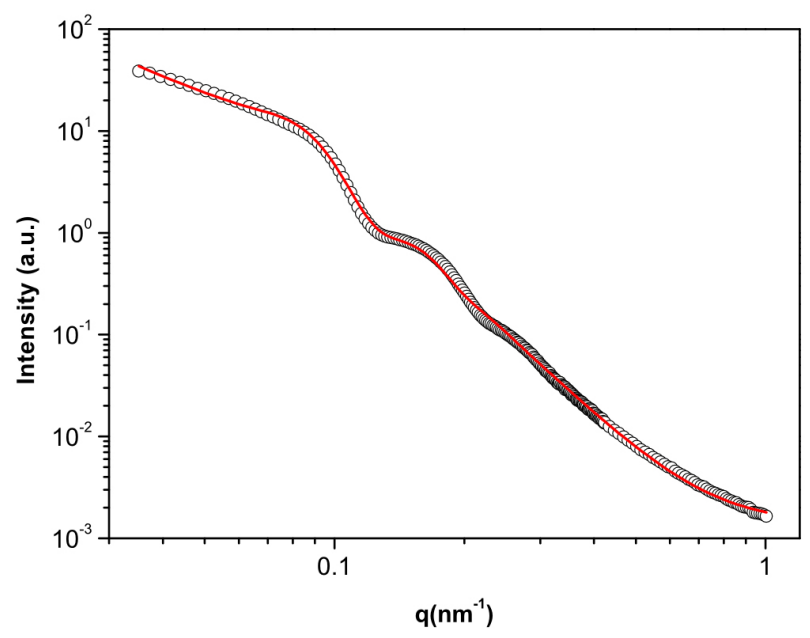

Figure 2. SAXS profile (open balls) of $\mathrm{CCM} / \mathrm{SiO}_{2}-\mathrm{NH}_{2}-400$ and its best corresponding fit (solid red line).

Similar SAXS profiles were observed for all studied systems (Figure S2, Supplementary Information section). For all of them, a polydisperse sphere model taking into account a Gaussian size distribution and subtle interparticle correlation at low- $q$ was applied. The quality of the SAXS fits (Figure 2) as well as the TEM images indicated that the nanoparticles are mainly spherical in shape. It was observed that the mean diameter determined from the fit for bare silica, $\mathrm{SiO}_{2}-\mathrm{NH}_{2}-200, \mathrm{SiO}_{2}-\mathrm{NH}_{2}-400, \mathrm{CCM} / \mathrm{SiO}_{2}-\mathrm{NH}_{2}-200$ and $\mathrm{CCM} / \mathrm{SiO}_{2}-\mathrm{NH}_{2}-400$ were 53,56 and $73,66,79$ and $71 \mathrm{~nm}$, respectively. It is important to highlight that these values are in close agreement with TEM images (Table 1).

The nitrogen adsorption/desorption isotherm for all samples are shown in Figure 3. All studied samples presented similar nitrogen adsorption/desorption isotherms. After functionalization and encapsulation, the isotherms of $\mathrm{SiO}_{2}-\mathrm{NH}_{2}-200, \mathrm{SiO}_{2}-\mathrm{NH}_{2}-400, \mathrm{CCM}-\mathrm{SiO}_{2}-\mathrm{NH}_{2}-200$ and $\mathrm{CCM}-\mathrm{SiO}_{2}-\mathrm{NH}_{2}-400$ kept the same characteristics of $\mathrm{SiO}_{2}$. There is almost no difference in the shape of the hysteresis loop, suggesting that the pore shape was not significantly changed after grafting with APTES and encapsulation with curcumin. However, the adsorbed nitrogen amount was reduced implying a decrease of pore volume of the particles.

According to IUPAC classification, mesoporous silica nanoparticles clearly show a type II isotherm with an H1 hysteresis loop that is often obtained for materials 
Table 1. Diameters and HWHMa ${ }^{a}$ obtained from different techniques and zeta potentials for different nanoparticles

\begin{tabular}{|c|c|c|c|c|c|}
\hline Sample & $\begin{array}{c}\text { Diameter by } \\
\text { TEM / nm }\end{array}$ & $\begin{array}{l}\text { HWHM by } \\
\text { TEM / nm }\end{array}$ & $\begin{array}{l}\text { Diameter by } \\
\text { SAXS / nm }\end{array}$ & $\begin{array}{l}\text { HWHM by } \\
\text { SAXS / nm }\end{array}$ & $\begin{array}{c}\text { Zeta potential in } \\
\mathrm{KCl}^{\mathrm{b}} / \mathrm{mV}\end{array}$ \\
\hline $\mathrm{SiO}_{2}$ & 52 & 13 & 56 & 8 & $-33.7 \pm 1.0$ \\
\hline $\mathrm{SiO}_{2}-\mathrm{NH}_{2}-200$ & 56 and 73 & 18 and 7 & 61 and 79 & 8 and 9 & $37.3 \pm 1.0$ \\
\hline $\mathrm{SiO}_{2}-\mathrm{NH}_{2}-400^{\mathrm{b}}$ & 62 & 22 & 66 & 17 & $37.1 \pm 1.1$ \\
\hline $\mathrm{CCM} / \mathrm{SiO}_{2}-\mathrm{NH}_{2}-200$ & 76 and 107 & 17 and 8 & $79^{c}$ & 14 & $33.0 \pm 0.8$ \\
\hline $\mathrm{CCM} / \mathrm{SiO}_{2}-\mathrm{NH}_{2}-400^{\mathrm{b}}$ & 66 & 13 & 71 & 12 & $27.6 \pm 1.2$ \\
\hline
\end{tabular}

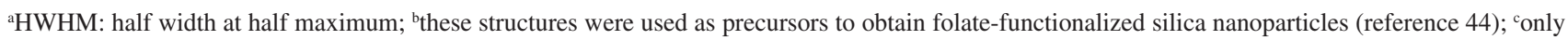
one size distribution was enough to properly fit the scattering data; TEM: transmission electron microscopy; SAXS: small-angle X-ray scattering.
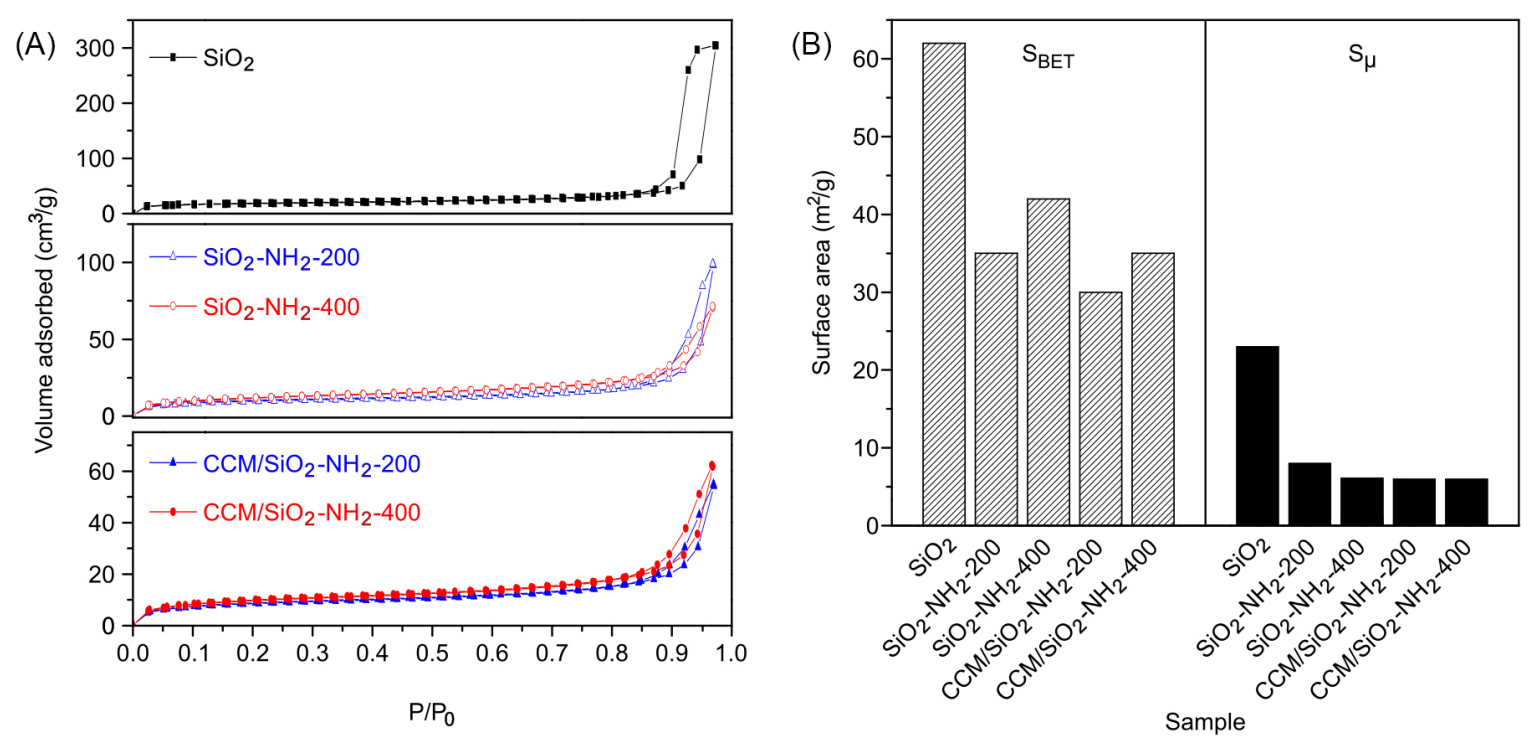

Figure 3. (A) Nitrogen adsorption-desorption isotherms of $\mathrm{SiO}_{2}, \mathrm{SiO}_{2}-\mathrm{NH}_{2}-200, \mathrm{SiO}_{2}-\mathrm{NH}_{2}-400, \mathrm{CCM} / \mathrm{SiO}_{2}-\mathrm{NH}_{2}-200$ and CCM/SiO $2-\mathrm{NH}_{2}-400$; (B) surface area determined by BET $\left(\mathrm{S}_{\mathrm{BET}}\right)$ and $t$-Plot $(\mathrm{S} \mu)$ tests for all studied samples.

consisting of agglomerates or compacts of approximately uniform spheres. ${ }^{58}$ For all the materials, $t$-Plot analysis $\left(\mathrm{S}_{\mu}\right)$ indicated that most of the specific surface area was located in mesopores $\left(\mathrm{S}_{\mathrm{BET}}\right)$. This result agrees well with the literature $^{59}$ that describes Stöber silica particles containing microporous and mesoporous compartments in their structure. In a previous study, ${ }^{44}$ using high-resolution transmission electron microscopy, we showed that this type of materials is formed by elementary silica spheres.

The FTIR spectra of the bare silica (1), $\mathrm{SiO}_{2}-\mathrm{NH}_{2}-400$ (2b) and $\mathrm{CMC} / \mathrm{SiO}_{2}-\mathrm{NH}_{2}-400(\mathbf{4 b})$ were obtained to characterize the chemical bonds and surface organic groups in mesoporous silica nanoparticles. FTIR of (1) is presented in Figure 4 (dashed blue line) where absorption bands due to $\mathrm{OH}\left(3446 \mathrm{~cm}^{-1}\right), \mathrm{H}_{2} \mathrm{O}\left(1635 \mathrm{~cm}^{-1}\right), \mathrm{Si}-\mathrm{O}-\mathrm{Si}$ $\left(v_{\text {as }} 1097 \mathrm{~cm}^{-1}, v_{\mathrm{s}} 796 \mathrm{~cm}^{-1}\right)$ and $\mathrm{Si}-\mathrm{OH}\left(v_{\mathrm{s}} 960 \mathrm{~cm}^{-1}\right)$ bonds are observed (the whole FTIR spectra is presented in the Supplementary Information section Figure S3). After reaction with APTES, the FTIR spectrum shows new absorption peaks observed at 2920, 2850 and $1470 \mathrm{~cm}^{-1}$,

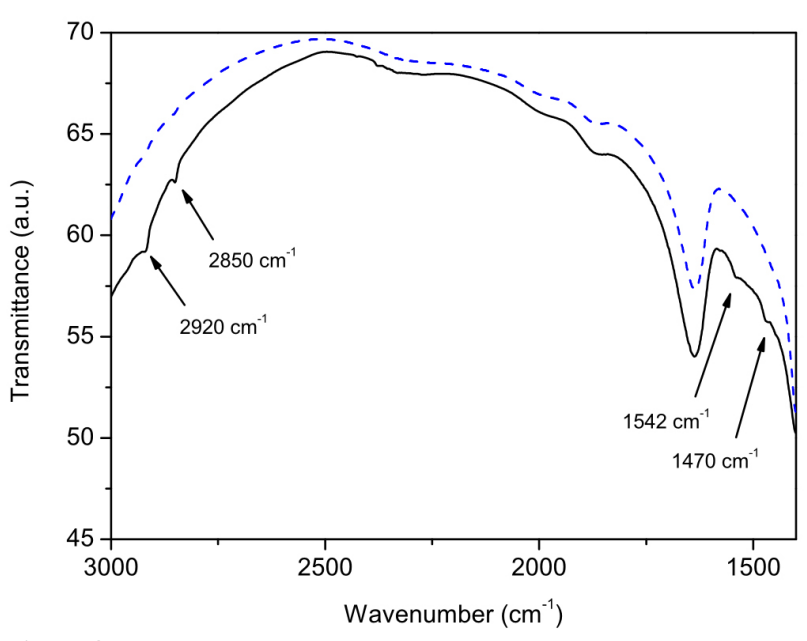

Figure 4. FTIR spectra of bare silica (dashed blue line) and $\mathrm{SiO}_{2}-\mathrm{NH}_{2}-400$ (solid black line).

which are assigned to $\mathrm{C}-\mathrm{H}$ stretching and bending vibrations from the aminopropyl groups, respectively (solid black line). The presence of amino groups was also confirmed through the weak absorption at $1542 \mathrm{~cm}^{-1}$, 
which is attributed to typical bending vibration of $\mathrm{NH}_{2}$. For $\mathrm{CCM} / \mathrm{SiO}_{2}-\mathrm{NH}_{2}-400(\mathbf{4 b})$, the absorption peaks of curcumin could not be observed. This result was expected since the amount of curcumin compared to silica is considerably small and the equipment is not sensitive enough to detect such small amount of CCM.

Zeta potential was also employed to confirm the encapsulation of curcumin seen by UV-Vis. The surface charge measured as zeta potential is presented in Table 1 for all nanoparticles. The zeta potential provides the nanoparticles surface charge and can be also related to the colloidal dispersions stability. A higher zeta potential results in a larger electrostatic repulsion between the particles decreasing the aggregation and providing improved stability to the dispersion. Colloids with low zeta potential tend to undergo aggregation. A value of $30 \mathrm{mV}$ or higher in module (positive or negative) can be taken as a theoretical value to indicate colloidal stability. Samples with zeta potential between -30 and $+30 \mathrm{mV}$ typically tend to aggregate. The zeta potential of bare silica is negative due to the negatively charged hydroxyl groups on the silica surface. As expected, $\mathrm{SiO}_{2}-\mathrm{NH}_{2}(\mathbf{2} \mathbf{a}$ and $\mathbf{2 b}$ ) presents positive value for zeta potential, indicating that the silanol groups were covalently bonded to the APTES molecules. For $\mathrm{CCM} / \mathrm{SiO}_{2}-\mathrm{NH}_{2}(\mathbf{4 a}$ and $\mathbf{4 b})$, a slight decrease in zeta potential occurs due to the presence of curcumin in the nanoparticle. This is likely due to the presence of curcumin fraction that might be found on the nanoparticles surface. These results confirm the presence of amino groups and encapsulated curcumin into/onto the mesoporous silica. As one can observe, the absolute values measured indicate that the nanoparticles are within the stable colloidal range. In addition, DLS of these nanoparticles was measured in biological media. These results together with CCM delivery experiments are presented in the Supplementary Information section as Figures S4 and S5.

Nanoparticles bactericidal properties were evaluated against $E$. coli as a typical gram-negative bacterium using the viable cell count method which measures the bacterial growth. For this study, $\mathrm{SiO}_{2}, \mathrm{SiO}_{2}-\mathrm{NH}_{2}-200, \mathrm{SiO}_{2}-\mathrm{NH}_{2}-400$, $\mathrm{CCM} / \mathrm{SiO}_{2}-\mathrm{NH}_{2}-200$ and $\mathrm{CCM} / \mathrm{SiO}_{2}-\mathrm{NH}_{2}-400(\mathbf{1}, \mathbf{2 a}$, $\mathbf{2 b}, \mathbf{4 a}$ and $\mathbf{4 b}$, respectively) were inoculated with E. coli solution in LB broth. The total mass for each structure was deduced based on the amount of curcumin encapsulated in each nanoparticle (details are given in the Supplementary Information section). Thus, $32 \mathrm{mg}$ for the silica structures $\mathbf{2 a}$ and $\mathbf{4 a}$ were used, while for $\mathbf{2 b}$ and $\mathbf{4 b}$, $13 \mathrm{mg}$ were employed. As a point of comparison, we have also chosen to use two amounts of silica (13 and $32 \mathrm{mg}$, samples were named $\mathrm{SiO}_{2}-13$ and $\mathrm{SiO}_{2}-32$, respectively) to evaluate the effect of bare silica amount against $E$. coli.
On the other hand, curcumin is insoluble in LB broth and, therefore, could not be used as control. Figure 5 shows the percentage of surviving $E$. coli for all nanoparticles. The figure is divided considering the total incubated mass per experiment.

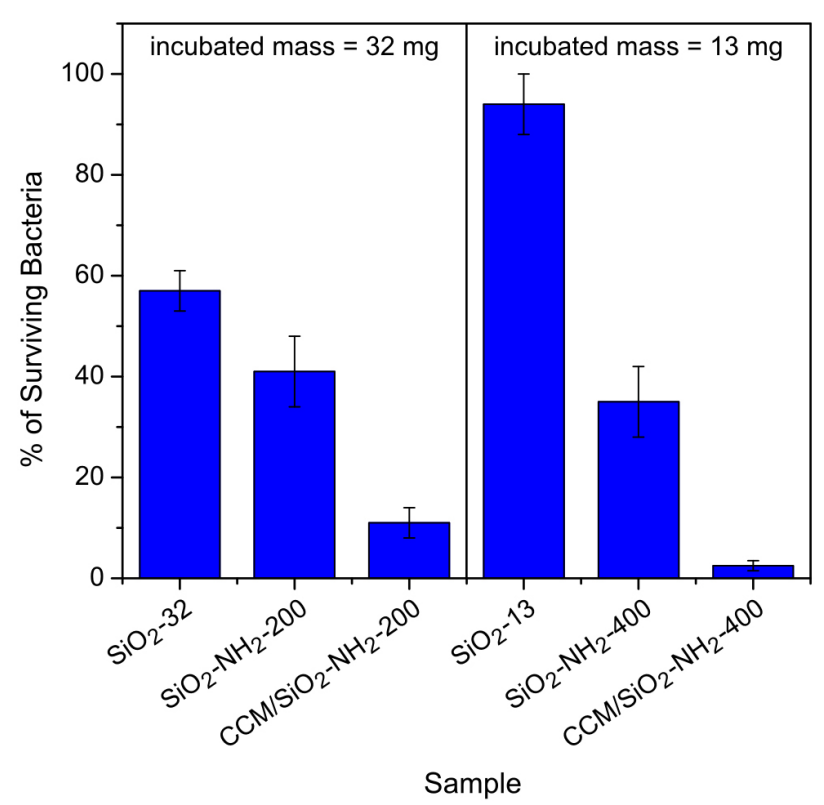

Figure 5. Antimicrobial activity of silica nanoparticles against gramnegative $E$. coli bacterium. Bar representation indicates the percentage of surviving bacteria. Details about samples' composition are presented in the Supplementary Information section.

The percentages of surviving bacteria for $\mathrm{SiO}_{2}-32$, $\mathrm{SiO}_{2}-\mathrm{NH}_{2}-200, \mathrm{CCM} / \mathrm{SiO}_{2}-\mathrm{NH}_{2}-200, \mathrm{SiO}_{2}-13$, $\mathrm{SiO}_{2}-\mathrm{NH}_{2}-400$ and $\mathrm{CCM} / \mathrm{SiO}_{2}-\mathrm{NH}_{2}-400$ were $57 \pm 4$, $40 \pm 7,11 \pm 3,94 \pm 4,36 \pm 7$ and $3 \pm 1 \%$, respectively. For samples of bare silica $\left(\mathrm{SiO}_{2}-32\right.$ and $\left.\mathrm{SiO}_{2}-13\right)$, the antimicrobial activity is diminished as the concentration of the silica is reduced. $\mathrm{SiO}_{2}-\mathrm{NH}_{2}-200$ (2a) and $\mathrm{SiO}_{2}-$ $\mathrm{NH}_{2}-400$ (2b) had enhanced biocidal efficacy than their bare silica counterparts, regardless of the quantities employed $\mathrm{SiO}_{2}-13$ and $\mathrm{SiO}_{2}-32$. This effective antibacterial performance of silica nanoparticles without curcumin can be explained taking into account the influence of particle sizes and surface charges. According to the literature, ${ }^{46}$ smaller particles exhibit enhanced bactericidal activity than the larger ones. However, our results do not follow this trend. Although bare silica (1) presents smaller size than the amine-coated nanoparticles ( $\mathbf{2} \mathbf{a}$ and $\mathbf{2 b}$ ), $\mathrm{SiO}_{2}-\mathrm{NH}_{2}$ was more effective to prevent bacterial growth. Therefore, it is clear that the subtle difference in particle size (Table 1) is not able to explain these bactericidal efficiency results. Thus, we suggest that the surface charge contribution seems to be more important to the bactericidal activity than the particle size for this particular case (similar nanoparticles sizes). 
The zeta potential measurements for $\mathrm{SiO}_{2}-\mathrm{NH}_{2}(\mathbf{2 a}$ and 2b) exhibit positive values due to the positively charged amine groups on the silica surface (Table 1). As the bacterial cell surface is negatively charged, it is expected that the electrostatic attraction with the positively charged nanoparticles can be enhanced if compared to the negatively charged ones. ${ }^{44,60,61}$ Thereby, $\mathrm{SiO}_{2}-\mathrm{NH}_{2}$ nanoparticules (2a and $\mathbf{2 b}$ ) are more electrostatically attracted by negative bacterial cell surface than $\mathrm{SiO}_{2}(\mathbf{1})$ resulting in superior bactericidal properties. When comparing the results for $\mathrm{SiO}_{2}-\mathrm{NH}_{2}-200$ and $\mathrm{SiO}_{2}-\mathrm{NH}_{2}-400$ (2a and $\mathbf{2 b}$ ), we observed that the bactericidal efficacy is very similar. However, it is important to emphasize that the amount of $\mathrm{SiO}_{2}-\mathrm{NH}_{2}-200$ used along the tests is much higher (around three times larger) than that of $\mathrm{SiO}_{2}-\mathrm{NH}_{2}-400$. Hu et al. ${ }^{62}$ reported that the cationic amino groups can associate with anions on the bacterial wall, suppress its biosynthesis, disrupt the mass transport across the wall and accelerate the death of the bacteria. Thus, our results are in agreement with their findings and the presence and amount of amino groups were essential in the bacterial growth inhibition.

Nanoparticles containing curcumin $\left(\mathrm{CCM} / \mathrm{SiO}_{2}-\mathrm{NH}_{2}-200\right.$ and $\mathrm{CCM} / \mathrm{SiO}_{2}-\mathrm{NH}_{2}-400$ ) exhibited superior bactericidal effects when compared with other nanoparticles. It is important to highlight here that when the synthesis of bare silica is performed in the presence of curcumin (3), the total drug load is very low. Due to the small amount of curcumin, the bactericidal efficiency of $\mathrm{CCM} / \mathrm{SiO}_{2}(3)$ is very close to the one of $\mathrm{SiO}_{2}(\mathbf{1}) . \mathrm{SiO}_{2}-\mathrm{NH}_{2}$ samples (2a and $\mathbf{2 b}$ ) and $\mathrm{CCM} / \mathrm{SiO}_{2}-\mathrm{NH}_{2}$ (4a and $\mathbf{4 b}$ ) exhibit similar particle sizes and surface charges, which demonstrate that the bactericidal effect differences can be attributed to the curcumin presence. In addition, the differences in the results obtained between $\mathrm{CCM} / \mathrm{SiO}_{2}-\mathrm{NH}_{2}-200$ (4a) and $\mathrm{CCM} / \mathrm{SiO}_{2}-\mathrm{NH}_{2}-400$ (4b) cannot be explained by surface charge effect since all structures present similar zeta potentials. In this case, the nanoparticles present slight difference in particle size and different amounts of amino groups on the surface. In addition, (4a) present a slightly larger amount of total CCM if compared to sample (4b). The $\mathrm{CCM} / \mathrm{SiO}_{2}-\mathrm{NH}_{2}-200$ exhibits nanoparticles with two populations and large size distribution. On the order hand, $\mathrm{CCM} / \mathrm{SiO}_{2}-\mathrm{NH}_{2}-400$ has a monomodal distribution, larger curcumin intra-particle load and higher contribution due to the amino groups density on the nanoparticles surface. Our results highlight that the bactericidal properties of curcumin were maintained after encapsulation and that the contribution of the amino groups is essential during bacterial growth inhibition. Thus, a dual bactericidal system was obtained due to the presence of curcumin associated to the amine group on the nanoparticles surface.
Katsu et al. ${ }^{63}$ reported that the outer membrane of gramnegative bacteria prevents the penetration of hydrophobic antibiotics into cells. Hence, the cationic compounds are used to enhance the permeability of the outer membrane and thereby increase the sensitivity of gram-negative bacteria to several antibiotics. Thereby, we believe that curcumin had their bactericidal properties enhanced by the amino-functionalized silica. The interaction between the positively charged amino-functionalized silica and the negatively charged bacteria cell wall induces the preferential delivery of curcumin around the bacteria cell wall, leading to an increased local concentration of drug and consequent bacteria death. This strong interaction is also seen with mammalian cells since these nanoparticles present considerable toxicity especially after $48 \mathrm{~h}$ of incubation. This poisoning effect was somehow predicted since mammalian cells are highly susceptible to positively charged structures. ${ }^{44,60}$ Although we are sure that these nanoparticles cannot be used as single drug delivery vectors, the overall surface modification strategy as well as the nanoparticles presented here can definitively be incorporated into hybrid materials when cytotoxic effects are mitigated. Thus, we can envisage the use of our approach to produce composite materials with great potential as drug delivery vehicles since it is a versatile and mild method to solubilize and protect water-insoluble drugs while the nanoparticle surface can be tailored depending on the material as well as the final use.

\section{Conclusions}

We report here amino surface functionalization of silica nanoparticles as a strategy to increase the water-insoluble drug load and enhance antimicrobial properties. Tuning the amount of amino groups on the nanoparticles surface provides structures with distinct biological properties. The amount of water-insoluble drug effectively loaded into the mesoporous silica as well as the bactericidal activity response is considerably increased when the total amino grafting is augmented. The nanoparticles dual bactericidal activity is justified due to the possibility of increasing the water-insoluble drug load and enhancing the nanoparticles interaction with bacteria membrane through electrostatic attraction. The relationship between activity and structure indicated that surface chemistry is a major and important point in nanoparticles antibacterial properties that must be used in the rational design of new antibiotics based on nanoparticles. Finally, the strategy described here can also be customized to other kinds of antibiotics or surface functionalization, bringing to our approach an ample scientific and technological relevance. 


\section{Supplementary Information}

Supplementary data including TEM and size distribution images, SAXS profile, FTIR spectra, DLS measurements in biological media, curcumin release and detailed samples description for biological experiments are available free of charge at http://jbcs.sbq.org.br as a PDF file.

\section{Acknowledgments}

M. B. C. would like to thank FAPESP (No. 2014/22322-2 and 2015/25406-5) and the productivity research fellowship granted by CNPq (No. 309107/2014-8). We acknowledge LNLS (CNPEM, Brazil) for SAXS measurements (proposal SAXS1-11058) and LNNano (CNPEM, Brazil) for TEM measurements (proposal TEM-MSC-15277).

\section{References}

1. Llor, C.; Bjerrum, L.; Ther. Adv. Drug Saf. 2014, 5, 229.

2. Boucher, H. W.; Talbot, G. H.; Benjamin, D. K.; Bradley, J.; Guidos, R. J.; Jones, R. N.; Murray, B. E.; Bonomo, R. A.; Gilbert, D.; Clin. Infect. Dis. 2013, 56, 1685.

3. Falagas, M. E.; Rafailidis, P. I.; Matthaiou, D. K.; Virtzili, S.; Nikita, D.; Michalopoulos, A.; Int. J. Antimicrob. Agents 2008, 32,450 .

4. Chen, L. F.; Chopra, T.; Kaye, K. S.; Med. Clin. North Am. 2011, 95, 647.

5. Adhikari, N.; J. Inst. Med. 2009, 31, 1.

6. Daniel, M. C.; Astruc, D.; Chem. Rev. 2004, 104, 293.

7. Cobley, C. M.; Chen, J.; Cho, E. C.; Wang, L. V.; Xia, Y.; Chem. Soc. Rev. 2011, 40, 44.

8. Huang, K.; Ma, H.; Liu, J.; Huo, S.; Kumar, A.; Wei, T.; Zhang, X.; Jin, S.; Gan, Y.; Wang, P. C.; He, S.; Zhang, X.; Liang, X. J.; ACS Nano 2012, 6, 4483.

9. Redl, F. X.; Black, C. T.; Papaefthymiou, G. C.; Sandstrom, R. L.; Yin, M.; Zeng, H.; Murray, C. B.; O’Brien, S. P.; J. Am. Chem. Soc. 2004, 126, 14583.

10. Lee, J. E.; Lee, N.; Kim, H.; Kim, J. H. J. H.; Choi, S. H.; Kim, T.; Song, I. C.; Park, S. P.; Moon, W. K.; Hyeon, T.; J. Am. Chem. Soc. 2010, 132, 552.

11. Tu, H.-L.; Lin, Y.-S.; Lin, H.; Hung, Y.; Lo, L.; Chen, Y.; Mou, C.; Adv. Mater. 2009, 21, 172.

12. Kim, J.; Lee, J. E.; Lee, J.; Jang, Y.; Kim, S. W.; An, K.; Yu, J. H.; Hyeon, T.; Angew. Chem., Int. Ed. 2006, 45, 4789.

13. Lin, Y. S.; Hung, Y.; Lin, H. Y.; Tseng, Y. H.; Chen, Y. F.; Mou, C. Y.; Adv. Mater. 2007, 19, 577.

14. Vivero-Escoto, J. L.; Slowing, I. I.; Trewyn, B. G.; Lin, V. S.-Y.; Small 2010, 6, 1952.

15. Vallet-Regí, M.; Balas, F.; Arcos, D.; Angew. Chem., Int. Ed. 2007, 46, 7548 .
16. Cotí, K. K.; Belowich, M. E.; Liong, M.; Ambrogio, M. W.; Lau, Y.; Khatib, H.; Zink, J. I.; Khashab, N. M.; Stoddart, J. F.; Nanoscale 2009, 1, 16.

17. Trewyn, B. G.; Slowing, I. I.; Giri, S.; Chen, H.-T.; Lin, V. S.-Y.; Acc. Chem. Res. 2007, 40, 846.

18. Saha, S.; Leung, K. C. F.; Nguyen, T. D.; Stoddart, J. F.; Zink, J. I.; Adv. Funct. Mater. 2007, 17, 685.

19. Rosenholm, J. M.; Sahlgren, C.; Linden, M.; Nanoscale 2010, 2, 1870 .

20. Ambrogio, M. W.; Thomas, C. R.; Zhao, Y. L.; Zink, J. I.; Stoddart, J. F.; Acc. Chem. Res. 2011, 44, 903.

21. Bagwe, R. P.; Hilliard, L. R.; Tan, W.; Langmuir 2006, 22, 4357.

22. Maria Chong, A. S.; Zhao, X. S.; Appl. Surf. Sci. 2004, 237, 398.

23. Cauda, V.; Schlossbauer, A.; Kecht, J.; Zürner, A.; Bein, T.; J. Am. Chem. Soc. 2009, 131, 11361.

24. Möller, K.; Kobler, J.; Bein, T.; Adv. Funct. Mater. 2007, 17, 605.

25. Lü, Y.; Lu, G.; Wang, Y.; Guo, Y.; Guo, Y.; Zhang, Z.; Wang, Y.; Liu, X.; Adv. Funct. Mater. 2007, 17, 2160.

26. Sevimli, F.; Yilmaz, A.; Microporous Mesoporous Mater. 2012 , $158,281$.

27. Chu, L.; Daniels, M. W.; Francis, L. F.; Chem. Mater. 1997, 9 , 2577.

28. Nieto, A.; Colilla, M.; Balas, F.; Vallet-Regí, M.; Langmuir 2010, 26, 5038.

29. Puddu, V.; Perry, C. C.; Langmuir 2014, 30, 227.

30. Kim, S. T.; Saha, K.; Kim, C.; Rotello, V. M.; Acc. Chem. Res. 2013, 46, 681 .

31. Mout, R.; Moyano, D. F.; Rana, S.; Rotello, V. M.; Chem. Soc. Rev. 2012, 41, 2539.

32. Moyano, D. F.; Saha, K.; Prakash, G.; Yan, B.; Kong, H.; Yazdani, M.; Rotello, V. M.; ACS Nano 2014, 8, 6748.

33. Hoffmann, F.; Cornelius, M.; Morell, J.; Fröba, M.; Angew. Chem., Int. Ed. 2006, 45, 3216.

34. Tarn, D.; Ashley, C. E.; Xue, M.; Carnes, E. C.; Zink, J. I.; Brinker, C. J.; Acc. Chem. Res. 2013, 46, 792.

35. Du, X.; He, J.; Langmuir 2011, 27, 2972.

36. Jin, D.; Park, K.-W.; Lee, J. H.; Song, K.; Kim, J.-G.; Seo, M. L.; Jung, J. H.; J. Mater. Chem. 2011, 21, 3641.

37. Siddharth Jambhrunkar, Surajit Karmakar, Amirali Popat, M. Y. C. Y.; $R S C A d v$. 2014, 4, 1166.

38. Hamam, F.; Al-Remawi, M.; J. Funct. Foods 2014, 8, 87.

39. Jambhrunkar, S.; Qu, Z.; Popat, A.; Yang, J.; Noonan, O.; Acauan, L.; Ahmad Nor, Y.; Yu, C.; Karmakar, S.; Mol. Pharm. 2014, 11, 3642.

40. Singh, S. P.; Sharma, M.; Gupta, P. K.; Int. J. Biol. Macromol. 2015, 74, 162.

41. Kim, S.; Philippot, S.; Fontanay, S.; Duval, R. E.; Lamouroux, E.; Canilho, N.; Pasc, A.; RSC Adv. 2015, 5, 90550. 
42. Wang, J.; Wang, Y.; Liu, Q.; Yang, L.; Zhu, R.; Yu, C.; Wang, S.; ACS Appl. Mater. Interfaces, in press, DOI: acsami.6b08400.

43. Kotcherlakota, R.; Barui, A. K.; Prashar, S.; Fajardo, M.; Briones, D.; Rodríguez-Diéguez, A.; Patra, C. R.; Gómez-Ruiz, S.; Biomater. Sci. 2016, 4, 448.

44. de Oliveira, L. F.; Bouchmella, K.; Gonçalves, K. D. A.; Bettini, J.; Kobarg, J.; Cardoso, M. B.; Langmuir 2016, 32, 3217.

45. Datz, S.; Engelke, H.; Schirnding, C. V.; Nguyen, L.; Bein, T.; Microporous Mesoporous Mater. 2016, 225, 371.

46. dal Lago, V.; França de Oliveira, L.; de Almeida Gonçalves, K.; Kobarg, J.; Borba Cardoso, M.; J. Mater. Chem. 2011, 21, 12267.

47. França de Oliveira, L.; de Almeida Gonçalves, K.; Boreli, F. H.; Kobarg, J.; Cardoso, M. B.; J. Mater. Chem. 2012, 22, 22851.

48. Capeletti, L. B.; de Oliveira, L. F.; Gonçalves, K. D. A.; de Oliveira, J. F. A.; Saito, Â.; Kobarg, J.; dos Santos, J. H. Z.; Cardoso, M. B.; Langmuir 2014, 30, 7456.

49. de Oliveira, J. F. A.; Cardoso, M. B.; Langmuir 2014, 30, 4879.

50. França de Oliveira, L.; Gonçalves, J. O.; Gonçalves, K. D. A.; Kobarg, J.; Cardoso, M. B.; J. Biomed. Nanotechnol. 2013, 9 , 1817.

51. de Souza e Silva, J. M.; Pastorello, M.; Kobarg, J.; Cardoso, M. B.; Mazali, I. O.; ChemPhysChem 2013, 14, 4075.

52. Silva, H. F. O.; Lima, K. M. G.; Cardoso, M. B.; Oliveira, J. F. A.; Melo, M. C. N.; Sant'Anna, C.; Eugênio, M.; Gasparotto, L. H. S.; RSC Adv. 2015, 5, 66886.

53. Ribeiro de Barros, H.; Cardoso, M. B.; Camargo de Oliveira, C.; Cavichiolo Franco, C. R.; de Lima Belan, D.; Vidotti, M.; Riegel-Vidotti, I. C.; RSC Adv. 2016, 6, 9411.
54. de Souza e Silva, J. M.; Hanchuk, T. D. M.; Santos, M. I.; Kobarg, J.; Bajgelman, M. C.; Cardoso, M. B.; ACS Appl. Mater. Interfaces 2016, 8, 16564.

55. Stöber, W.; Fink, A.; Bohn, E.; J. Colloid Interface Sci. 1968, 26,62 .

56. Mahalingam, V.; Onclin, S.; Péter, M.; Ravoo, B. J.; Huskens, J.; Reinhoudt, D. N.; Langmuir 2004, 20, 11756.

57. Taylor, I.; Howard, A. G.; Anal. Chim. Acta 1993, 271, 77.

58. Leirose, G. D. S.; Cardoso, M. B.; J. Pharm. Sci. 2011, 100, 2826.

59. Szekeres, M.; Dékány, I.; de Keizer, A.; Colloids Surf., A 1998 , 141, 327.

60. Catherine, M. G.; Cusker, C. D. M.; Tuna, Y.; Rotello, V. M.; Bioconjugate Chem. 2004, 15, 897.

61. Hayden, S. C.; Zhao, G.; Saha, K.; Phillips, R. L.; Li, X.; Miranda, O. R.; Rotello, V. M.; El-Sayed, M. A.; Schmidt-Krey, I.; Bunz, U. H. F.; J. Am. Chem. Soc. 2012, 134, 6920.

62. Hu, S. G.; Jou, C. H.; Yang, M. C.; Biomaterials 2003, 24, 2685.

63. Katsu, T.; Nakagawa, H.; Yasuda, K.; Antimicrob Agents Chemother. 2002, 46, 1073.

Submitted: September 19, 2016 Published online: February 6, 2017

FAPERGS/CAPES has sponsored the publication of this article. 